\title{
Composition and genetics of malaria vector populations in the Central African Republic
}

Mamadou Ousmane Ndiath ${ }^{1,2 \dagger}{ }^{1}$, Karin Eiglmeier ${ }^{3,4^{*}}$ (D), Marina Lidwine Olé Sangba ${ }^{1,5}$, Inge Holm², Mirdad Kazanji ${ }^{6,7}$ and Kenneth D. Vernick ${ }^{3,4}$

\begin{abstract}
Background: In many African countries malaria has declined sharply due to a synergy of actions marked by the introduction of vector control strategies, but the disease remains a leading cause of morbidity and mortality in Central African Republic (CAR). An entomological study was initiated with the aim to characterize the malaria vectors in Bangui, the capital of CAR, and determine their vector competence.

Methods: A cross-sectional entomological study was conducted in 15 sites of the district of Bangui, the capital of CAR, in September-October 2013 and a second collection was done in four of those sites between November and December 2013. Mosquitoes were collected by human landing catch (HLC) indoors and outdoors and by pyrethrum spray catch of indoor-resting mosquitoes. Mosquitoes were analysed for species and multiple other attributes, including the presence of Plasmodium falciparum circumsporozoite protein or DNA, blood meal source, 2La inversion karyotype, and the L1014F kdr insecticide resistance mutation.

Results: Overall, 1292 anophelines were analysed, revealing a predominance of Anopheles gambiae and Anopheles funestus, with a small fraction of Anopheles coluzzii. Molecular typing of the An. gambiae complex species showed that An. gambiae was predominant (95.7 \%) as compared to An. coluzzii (2.1\%), and Anopheles arabiensis was not present. In some areas the involvement of secondary vectors, such as Anopheles coustani, expands the risk of infection. By HLC sampling, An. funestus displayed a stronger endophilic preference than mosquitoes from the An. gambiae sister taxa, with a mean indoor-capture rate of $54.3 \%$ and $67.58 \%$ for An. gambiae sister taxa and An. funestus, respectively. Human biting rates were measured overall for each of the species with 28 or 29 bites/person/night, respectively. Both vectors displayed a strong human feeding preference as determined by blood meal source, which was not different between the different sampling sites. An. coustani appears to be highly exophilic, with $92 \%$ of HLC samples captured outdoors. The mean CSP rate in head-thorax sections of all Anopheles was $5.09 \%$, and was higher in An. gambiae s.l. (7.4\%) than in An. funestus (3.3\%). CSP-positive An. coustani were also detected in outdoor HLC samples. In the mosquitoes of the An. gambiae sister taxa the kdr-w mutant allele was nearly fixed, with $92.3 \%$ resistant homozygotes, and no susceptible homozygotes detected.
\end{abstract}

Conclusions: This study collected data on anopheline populations in CAR, behaviour of vectors and transmission levels. Further studies should investigate the biting behaviour and susceptibility status of the anophelines to different insecticides to allow the establishment of appropriate vector control based on practical entomological knowledge.

\footnotetext{
*Correspondence: karin.eiglmeier@pasteur.fr

${ }^{+}$Mamadou Ousmane Ndiath and Karin Eiglmeier are equivalent first

authors

${ }^{3}$ Unit of Insect Vector Genetics and Genomics, Department of Parasites

and Insect Vectors, Institut Pasteur, 28 rue du Docteur Roux,

75015 Paris, France

Full list of author information is available at the end of the article
} 
Keywords: Anopheles, Insecticide resistance, Malaria, Bangui, Central African Republic

\section{Background}

Despite national and international efforts, the burden of malaria morbidity remains high, especially in tropical regions of Africa [1]. In Central African Republic (CAR), malaria remains a serious public health problem and is the leading cause of death among children. In the major part of the country, malaria is hyperendemic but the only detailed information available comes from the city of Bangui, in particular from the Hôpital Communautaire [2-4]. Only insufficient and inconsistent data are available from other areas of CAR due to the lack of resources and violent political conflicts. The country is plagued by shortages of essential drugs and logistical constraints, and access of the population to health care is far from being a reality.

Since July 2006, the Global Fund Programme for Malaria, through the Global Fund to Fight AIDS, Tuberculosis and Malaria has distributed free insecticide-treated nets (ITNs) to pregnant women and children under 5 years in all health centres and vaccination sites in CAR, but malaria remains endemic throughout the country. Today, preventing malaria relies on treatment of patients, and mosquito control interventions $[5,6]$ with the latter primarily based on the use of ITNs and indoor residual spraying. However, these efforts are threatened by the emergence of insecticide resistance in insect vectors [7].

Vector control can be effective in the long term only through a thorough understanding of the transmission cycles, the biology and ecology of vectors [8, 9]. Many malaria transmitting mosquitoes belong to species complexes with behavioural, environmental and genetic differences that influence their role as vectors $[8,10]$ and they can show important differences in malaria transmission $[11,12]$.

The knowledge about mosquito populations and malaria vectors in CAR is very limited. The most recent study focused on the epidemiology of yellow fever [13]. To the best of the authors' knowledge, no study has been conducted to determine the precise epidemiological role of mosquito species in malaria transmission and to collect a reference data set of entomological information that can serve to define appropriate control strategies adapted to the status of the species concerned.

The current study provides an inventory of malaria vectors present in Bangui, the capital of CAR, comprising data on vector biology, vector behaviour, the distribution of the L1014F $k d r$ resistance mutation and importance of anopheline species in transmission, constituting a baseline for entomologic and epidemiologic interventions.

\section{Methods}

Study area

CAR is a vast, sparsely populated country, covering $623,000 \mathrm{~km}^{2}$ with a population in 2015 of about 4.9 million inhabitants [14]. The country is surrounded by Cameroon to the West, Chad to the North, Sudan and Southern Sudan to the East, the Democratic Republic of Congo and the Congo to the South. The CAR climate is subequatorial, with temperatures varying from 19 to $32{ }^{\circ} \mathrm{C}$ and a rainy period between April and November. Malaria transmission occurs during the entire year, with peaks at the beginning and the end of the rainy season.

\section{Study design}

All mosquitoes in this study were collected during two cross-sectional studies. The first collection was performed during September-October 2013 (in the middle of the rainy season) and was conducted in 15 districts of Bangui, the capital of CAR: Gobongo, Gbanikola, Malimaka, Gbaya-Dombia, Greboutou, Taoka Saint Paul, PK 10, Yamangala, Yakité Dado, Ile de singe, Lakouanga, Dendégué II, Galabadja, Saïdou, Cité Jean XXIII; (Additional files 1,2). The second collection covered four districts (Gbanikola, Taoka Saint Paul, PK 10, Ile de singe) and was done in November-December. This second collection, initially planned as a broader longitudinal study of 2 consecutive years, had to be interrupted after the first weeks of collection because of political violence in December 2013. In all districts, GPS coordinates of mosquito collection sites were recorded.

\section{Mosquito collections}

Adult mosquitoes were collected by human landing catch (HLC) and pyrethrum spray catch (PSC). Hourly HLC were made on adult volunteers from 18:00 to 6:00 h for two consecutive nights at two indoor and two outdoor sites in typical households of the central part of the village.

Pyrethrum spray catches were conducted in five rooms in houses where insecticides or repellents had not been used during the previous week and that were different from houses used for HLC. For PSC, deltamethrin $\left(\right.$ Yotox $^{\circledR}$ ) was sprayed inside the closed rooms for 30-45 s. After $10 \mathrm{~min}$, dead or immobilized mosquitoes fallen on white sheets were collected in Petri dishes and brought to the laboratory. 


\section{Mosquito identification by morphology, blood-meal determination and CSP detection}

Anophelines were identified by the morphological identification keys of Gillies and De Meillon [15]. The blood meal of blood-fed females captured by PSC was squashed onto Whatman No. 1 filter paper and tested by ELISA to distinguish between bovine, ovine, caprine (sheep and goat), equine (horse and donkey) or chicken origin, as previously described [16]. The presence of circumsporozoite protein (CSP) of Plasmodium falciparum was determined using an enzyme-linked immunosorbent assay (ELISA-CSP) performed on the dissected head and thorax section [17].

\section{Mosquito DNA isolation}

Genomic DNA was extracted from individual mosquitoes of the second collection, regardless of whether they were visibly blood fed or not, using DNAzol according to the manufacturer's recommendations (Invitrogen, CA, USA). The total genomic DNA from each mosquito was resuspended in $100 \mu \mathrm{l} \mathrm{H}_{2} \mathrm{O}$ and stored at $-20{ }^{\circ} \mathrm{C}$ until use.

\section{Species determination and genotyping}

All DNA samples from the second collection were typed for species, molecular form and 2La inversion karyotype as described previously [18]. Briefly, species status and molecular form were determined by either or both of two diagnostic assays, the SINE200 X6.1 assay [19] or the molecular assay described by Fanello et al. [20], to allowed the discrimination of Anopheles arabiensis, Anopheles gambiae (formerly S molecular form) and Anopheles coluzzii (formerly M molecular form). If these assays failed to give diagnostic fragments, the ribosomal gene ITS2 spacer region or a region of the mitochondrial cytochrome $C$ oxidase I gene were PCR amplified and analysed. The $2 \mathrm{La}$ inversion type was determined using the published molecular assay [21]. Oligonucleotide primers with a $5^{\prime}$ fluorescent label were used in these three different assays that are based on polymerase chain reactions (PCR), permitting the sizing of the generated PCR fragments using an ABI Genetic Analyzer 3730 and called using Genemapper 3.5 (Applied Biosystems, CA, USA) for result analysis as described [18].

\section{Typing of the $k d r-w L 1014 F$ insecticide resistance mutation} Typing of the West African $k d r-w$ mutation (L1014F), thereafter identified as $k d r-w$, was done as described [18], briefly using the following primers and PCR conditions: Agd1 5'-ATA GAT TCC CCG ACC ATG-3', Agd2 5'-AGA CAA GGA TGA TGA ACC-3', Agd3 5'-AAT TTG CATT ACT TAC GAC A-3', Agd4 5'-CTG TAG TGA TAG GAA ATT TA-3'. PCR conditions consisted of an initial denaturing step at $94{ }^{\circ} \mathrm{C}$ for 5 min followed by 30 cycles of $94{ }^{\circ} \mathrm{C}$ for $30 \mathrm{~s}, 55^{\circ} \mathrm{C}$ for $30 \mathrm{~s}, 72{ }^{\circ} \mathrm{C}$ for $15 \mathrm{~s}$ and a final extension of $72{ }^{\circ} \mathrm{C}$ for $5 \mathrm{~min}$. The Agd1 and Agd4 primers were labeled with a fluorophore and the PCR fragments were separated on an ABI Genetic Analyzer 3730. All samples displayed a control band of 293 bp while resistant (1014 phe-coding) individuals displayed an additional $196 \mathrm{bp}$ band and susceptible (1014 leu-coding) individuals a $136 \mathrm{bp}$ band whereas heterozygous mosquitoes showed all three bands.

\section{Detection of Plasmodium parasites by PCR}

Plasmodium parasite presence was ascertained by PCR amplification of a portion of the Plasmodium mitochondrial cytochrome $b$ gene $(c y t B)$ following modifications of the protocols from Fornadel et al. [22] and Hasan et al. [23] as described in [24]. Amplicons were visualized by agarose gel electrophoresis. This Plasmodium detection assay was performed on DNA samples originating from all individual mosquitoes of the second collection, independent of whether the mosquito was visibly blood fed or not.

\section{ITS2 analysis}

The rDNA nuclear internal transcribed spacer 2 (ITS2) was amplified by PCR using primers described by Beebe and Saul [25], essentially according to the recommendations of the MR4 protocol [26]. In anopheline species the length of the amplified ITS2 fragments can vary according to the species. The amplicons were visualized by agarose gel electrophoresis and representatives of PCR fragments of different sizes were sequenced in the forward and reverse direction. Sequencing was performed at a commercial laboratory according to the recommended protocol for BigDye terminator cycle sequencing (Applied Biosystems, USA). Sequences were then compared by BLASTN against public databases to determine mosquito species from the most significant alignment.

\section{Amplification of mosquito mitochondrial cytochrome $C$ oxidase / gene}

A 749 bp region of the mitochondrial cytochrome $\mathrm{C}$ oxidase subunit 1 gene $(C O I)$ gene was amplified by PCR using the primers COI-forward 5'-GGA GGA TTT GGA AAT TGA TTA GTT CC-3 and COI-reverse 5'-GCT AAT CAT CTA AAA ATT TTA ATT CC-3', essentially as published [26]. The amplicons were sequenced in the forward and reverse direction by a commercial laboratory according to the recommended protocol for BigDye Terminator Cycle Sequencing (Applied Biosystems, USA). Consensus sequences were generated from forward and reverse reads and compared with the Barcode of Life [27] database for species identification. 


\section{Data analyses}

Qualitative data were compared using Pearson Chi Square or Fisher exact test and statistical analyses were performed with Stata 10.1. A $p$ value of 0.05 or less was considered as significant. The human biting rate was estimated from the number of bites per person per night sampled by HLC. The indoor-capture rate was calculated as the proportion of the number of mosquitoes captured indoors among the total number of mosquitoes captured indoors and outdoors by HLC. The anthropophily rate was calculated as the proportion of freshly fed mosquitoes that had taken at the time of capture an exclusively human blood meal among all fed mosquitoes. The infection rate was calculated as the proportion of Plasmodium positive mosquitoes to the total number of malaria vectors.

\section{Results}

In total, 1292 anophelines were collected between September and December 2013. The first collection, over 60 person-nights in 15 districts of Bangui, led to the capture of 825 anophelines by HLC (Additional files 1,2) and 227 anophelines by PSC. In the second collection, 197 anophelines were captured by HLC and 43 by PSC. Besides the predominant An. gambiae sister taxa and Anopheles funestus, other Anopheles species such as An. coustani, Anopheles natalensis and Anopheles pharoensis were also captured (Table 1).

\section{Human biting rate and nocturnal biting cycle}

The human biting rate (HBR) variations of mosquitoes of the An. gambiae sister taxa and An. funestus collected in 15 districts of Bangui are shown in Fig. 1. An. gambiae sister taxa are present in all districts with a maximum aggressiveness observed in Ile de singe, with 28 bites/ person/night $(\mathrm{B} / \mathrm{P} / \mathrm{N})$ and PK10 $(24 \mathrm{~B} / \mathrm{P} / \mathrm{N})$ whereas $A n$.

Table 1 Summary of the anophelines collected in Bangui by HLC and by PSC

\begin{tabular}{lccccr}
\hline Species & \multicolumn{2}{c}{ Human landing catch } & \multicolumn{2}{c}{$\begin{array}{l}\text { Pyrethrum spray } \\
\text { catch }\end{array}$} \\
\cline { 2 - 3 } & Indoor & Outdoor & & Indoor & Total \\
\hline An. gambiae sister taxa & 328 & 276 & & 198 & 802 \\
An. funestus & 171 & 82 & & 69 & 322 \\
An. coustani & 7 & 81 & & 1 & 89 \\
An. natalensis & 13 & 55 & & 0 & 68 \\
An.pharoensis & 0 & 9 & & 2 & 11 \\
Total & 519 & 503 & & 270 & 1292 \\
\hline
\end{tabular}

Mosquitoes were captured during the first collection (September-October 2013) in 15 districts of Bangui and during the second collection (November-December 2013) in four districts funestus is more prevalent in Gbanikola $(29.5 \mathrm{~B} / \mathrm{P} / \mathrm{N})$ and Taoka St. Paul $(23.5 \mathrm{~B} / \mathrm{P} / \mathrm{N})$. In the four districts these major malaria vectors are sympatric, showing a high HBR and, therefore, resulting in the highest combined bite density per night amongst the districts in this survey.

Night-biting cycles were similar for An. gambiae sister taxa mosquitoes and An. funestus. Mosquito aggressiveness gradually increased after 19:00 h until about 03:00 h, and then sharply declined (Fig. 2a). A similar trend was observed at sites where the higher number of sampled mosquitoes permitted a graphical representation, notably at Gbanikola (Fig. 2b) and Ile de singe (Fig. 2c). At Taoka St. Paul, although sample sizes per time point were smaller, the difference in aggressiveness between the mosquito species of this sample set seemed to be more pronounced. There mosquitoes from the An. gambiae sister taxa were more aggressive during the period from 21:00-23:00 h, while An. funestus biting was more active from about 02:00-05:00 h (Fig. 2d).

\section{Indoor-capture rate and human blood index}

Of the total 1022 specimens sampled by HLC in both collections, 519 (50.78\%) were collected indoor and 503 (49.21\%) outdoor. The mean indoor-capture rate was $54.3 \%$ and $67.58 \%$ for An. gambiae sister taxa and An. funestus, respectively. There was a significant difference in indoor-capture rate between An. gambiae sister taxa and An. funestus (Chi Square $=12.9, \mathrm{df}=1, p<0.0005$ ) with An. funestus appearing more endophilic while $A n$. gambiae sister taxa were captured in both locations. By contrast, the mean outdoor-capture rate of An. coustani was $92.0 \%$.

Blood meal origin was determined in 149 An. gambiae sister taxa and 21 An. funestus sampled by PSC $(\mathrm{n}=170)$. Of these, 133 were strictly of human origin $(73.23 \%)$ and 31 were from animals $(18.23 \%)$, with 24 of dog origin (77.42 \%), 7 from bovine (22.58 \%) and 6 consisted of a mixture of human and animal blood (3.53\%). The human blood index (HBI) of An. gambiae sister taxa mosquitoes and An. funestus was (81.8 \%) and (52.3\%) respectively, indicating a high degree of human-vector contact (Additional file 3). However, no significant difference of HBI was observed in these two important vector species (Chi Square $=1.31, p=0.251$ ). No significant variation by district was observed in the anthropophilic rate of An. gambiae sister taxa mosquitoes (Chi Square $=1.50, p=1.00$ ) (Fig. 3).

Determination of Plasmodium falciparum circumsporozoite protein rate

The P. falciparum circumsporozoite protein (CSP) rate was determined by ELISA-CSP. Of the 825 Anopheles specimens of the first collection captured by HLC and tested by 


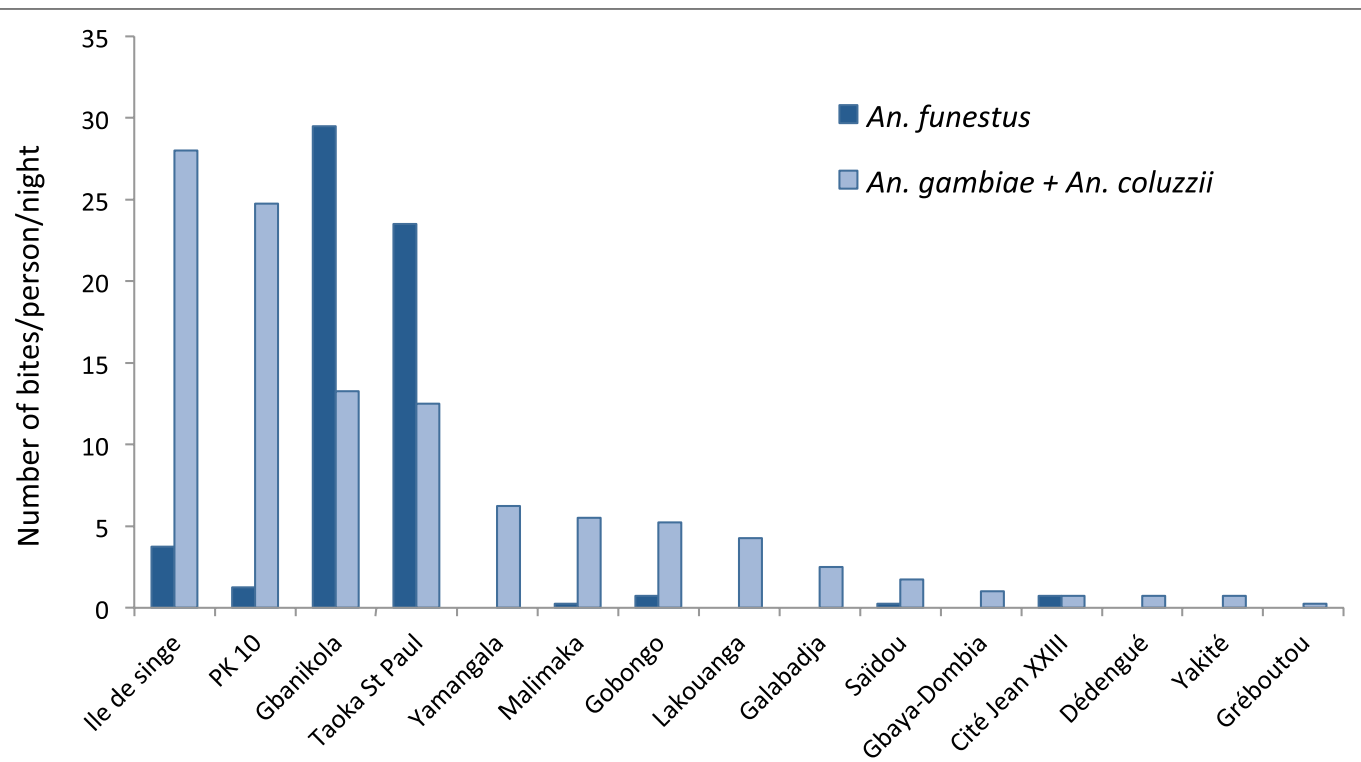

Fig. 1 Number of bites per person per night of Anopheles funestus and mosquitoes belonging to the Anopheles gambiae sister taxa (SeptemberOctober 2013). Mosquitoes ( $n=825$ ) were collected by HLC in 15 districts of Bangui

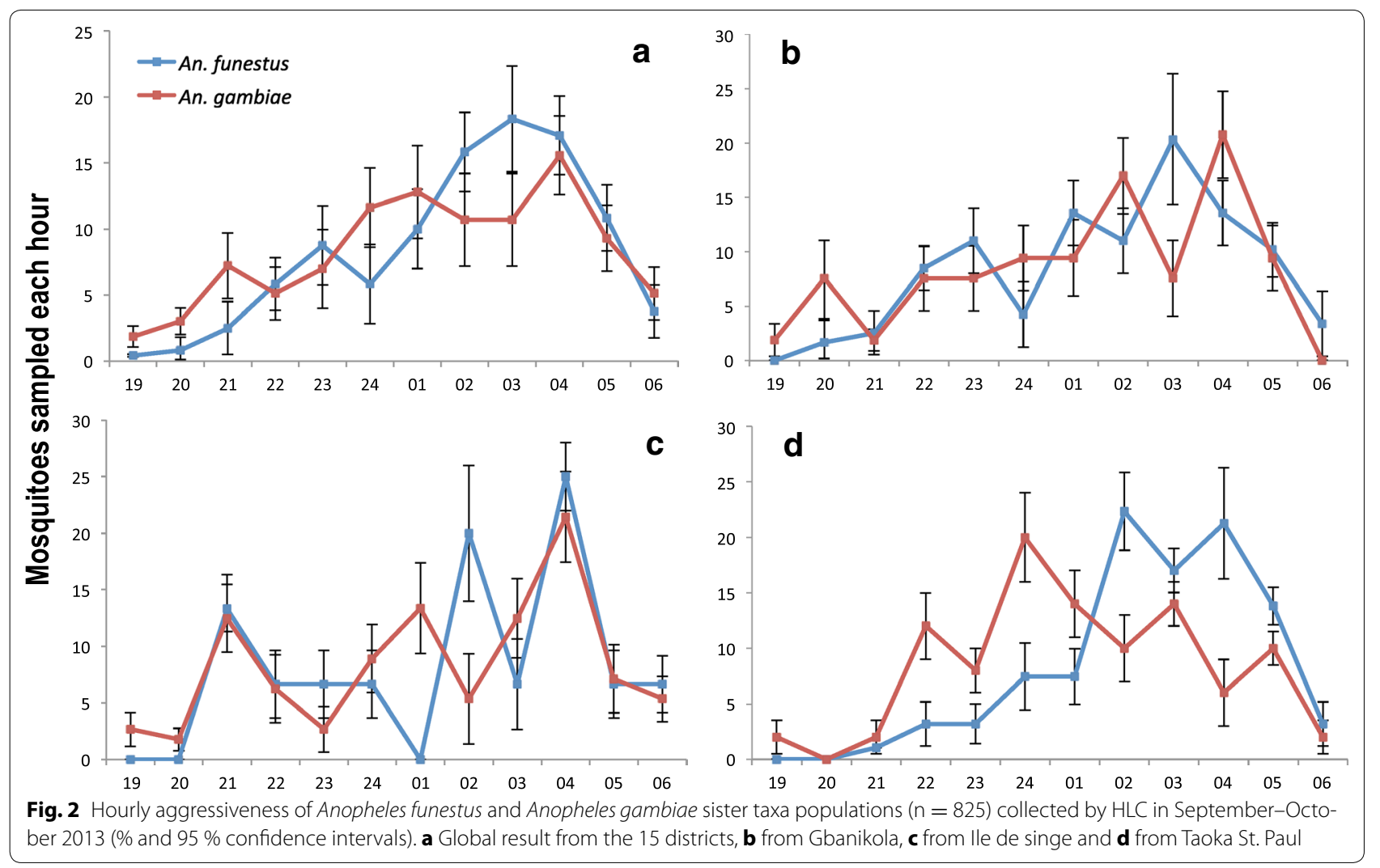

ELISA-CSP, 42 mosquitoes were positive for the CSP antigen (Table 2), resulting in a mean CSP of $5.09 \%$ with $7.4 \%$ and $3.33 \%$ for An. gambiae sister taxa and An. funestus, respectively (Chi Square $=4.15, p=0.041$ ). This was also reflected in the results from the An. gambiae sister taxa where the infection rate in indoor-captured mosquitoes of $10.3 \%(n=233$, number of positive mosquitoes $=24)$ that was significantly higher than those of outdoor-captured 


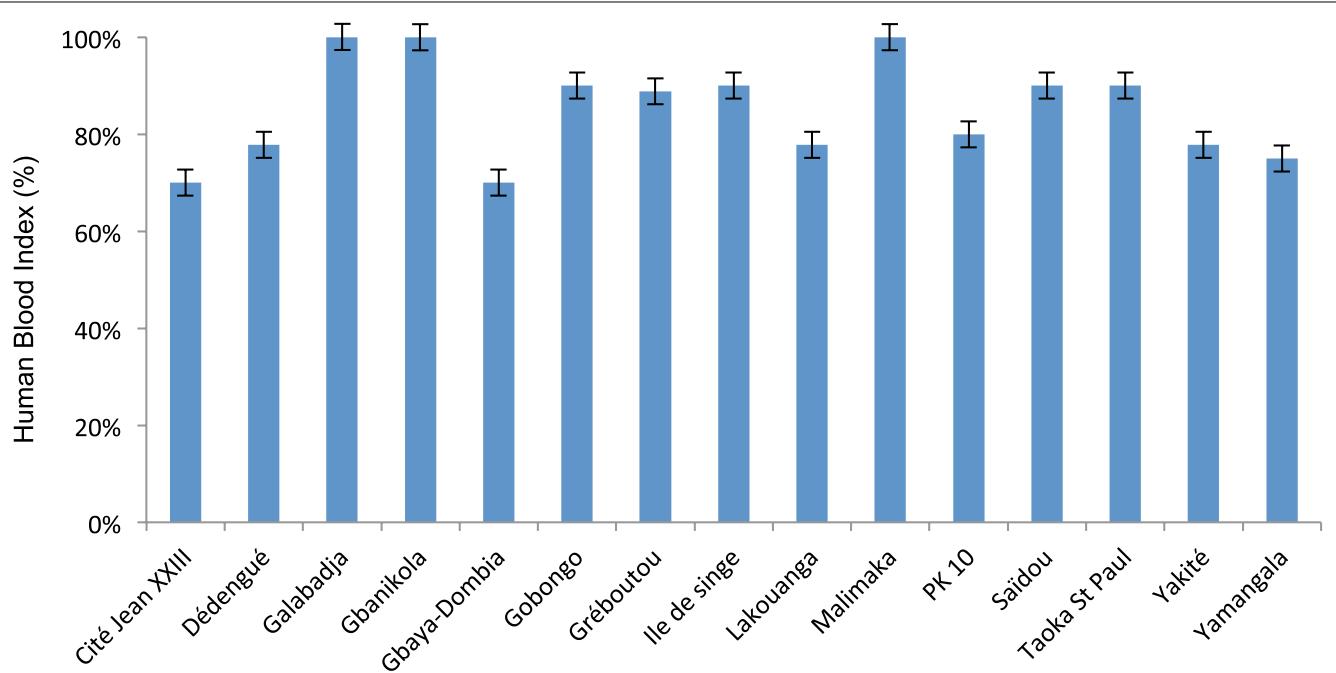

Fig. 3 Human blood index (proportion and $95 \%$ confidence interval) in 149 mosquitoes from Anopheles gambiae sister taxa (September-October 2013). Mosquitoes were collected by PSC in 15 districts of Bangui

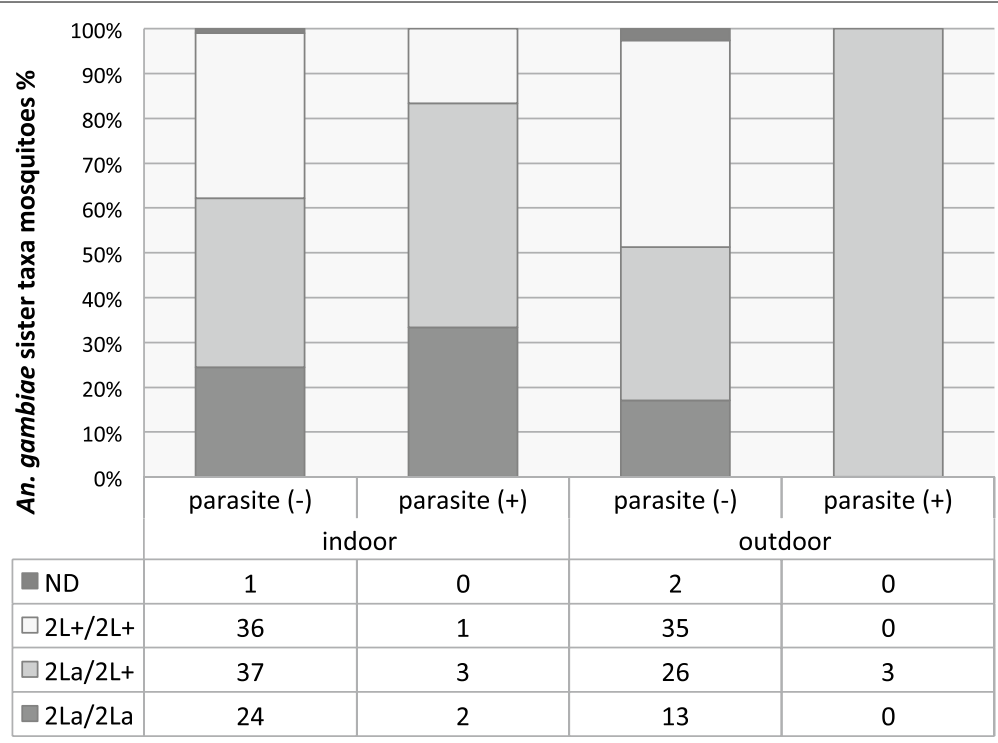

Fig. 4 Relation between 2 L chromosomal forms, Plasmodium parasite detection and place of capture (November-December 2013). Anopheles gambiae sister taxa $(n=183)$ were collected indoors and outdoors by HLC and PSC in four districts of Bangui

mosquitoes with $4.06 \%(\mathrm{n}=197$, number of positive mosquitoes $=8$, Additional file 4) (Chi Square $=5.2, p=0.02$ ). In addition, two An. coustani (captured outdoors) were positive for the CSP antigen in the district Ile de singe. This species presents a very strong tendency to exophily and may constitute a real risk of malaria transmission. None of the An. natalensis mosquitoes was found positive for CSP. Thus, $P$. falciparum positive mosquitoes were found at all collection sites except at Dédengué, Gbaya-Doumbia and
Greboutou, where the number of captured mosquitoes was very low (Table 2).

Mosquito identification and chromosomal characterization Of the 243 anophelines captured in the second collection (November-December 2013), 183 have been identified as mosquitoes belonging to the An. gambiae sister taxa using the molecular diagnostic assays with a predominance of An. gambiae $(\mathrm{n}=175)$ and few An. coluzzii $(\mathrm{n}=4)$. For 
Table 2 Detection of CSP antigen in mosquitoes collected by HLC in the 15 districts of Bangui (September-October 2013)

\begin{tabular}{|c|c|c|c|c|c|c|c|c|c|c|}
\hline \multirow[t]{2}{*}{ District } & \multicolumn{2}{|c|}{ An. funestus } & \multicolumn{2}{|c|}{ An. gambiae sister taxa } & \multicolumn{2}{|c|}{ An. coustani } & \multicolumn{2}{|c|}{ An. natalensis } & \multicolumn{2}{|l|}{ Total } \\
\hline & Tested & $\mathrm{CSP}+$ & Tested & $\mathrm{CSP}+$ & Tested & $\mathrm{CSP}+$ & Tested & $\mathrm{CSP}+$ & Tested & $\mathrm{CSP}+$ \\
\hline Cité Jean XIII & 3 & 1 & 3 & 0 & 0 & NA & 0 & NA & 6 & 1 \\
\hline Dédengué & 0 & NA & 3 & 0 & 0 & NA & 0 & NA & 3 & 0 \\
\hline Galabadjia & 0 & NA & 10 & 1 & 0 & NA & 0 & NA & 10 & 1 \\
\hline Gbanikola & 118 & 4 & 53 & 6 & 3 & 0 & 15 & 0 & 189 & 10 \\
\hline Gbaya-Doumbia & 0 & NA & 4 & 0 & 0 & NA & 5 & 0 & 9 & 0 \\
\hline Gobongo & 3 & 0 & 21 & 2 & 0 & NA & 0 & NA & 24 & 2 \\
\hline Greboutou & 0 & NA & 1 & 0 & 0 & NA & 7 & 0 & 8 & 0 \\
\hline lle de Singe & 15 & 1 & 112 & 3 & 82 & 2 & 13 & 0 & 222 & 6 \\
\hline Lakouanga & 0 & NA & 17 & 1 & 0 & NA & 5 & 0 & 22 & 1 \\
\hline Malimaka & 1 & 0 & 22 & 1 & 0 & NA & 0 & NA & 23 & 1 \\
\hline PK10 & 5 & 0 & 99 & 6 & 2 & 0 & 7 & 0 & 113 & 6 \\
\hline Saïdou & 1 & 0 & 7 & 1 & 0 & NA & 0 & NA & 8 & 1 \\
\hline Taoka St Paul & 94 & 2 & 50 & 6 & 0 & NA & 16 & 0 & 160 & 8 \\
\hline Yakité & 0 & NA & 3 & 1 & 0 & NA & 0 & NA & 3 & 1 \\
\hline Yamangala & 0 & NA & 25 & 4 & 0 & NA & 0 & NA & 25 & 4 \\
\hline Total & 240 & 8 & 430 & 32 & 87 & 2 & 68 & 0 & 825 & 42 \\
\hline Mean CSP rate & $3.33 \%$ & & $7.4 \%$ & & $2.29 \%$ & & $0 \%$ & & $5.09 \%$ & \\
\hline
\end{tabular}

Mosquitoes were captured during the first collection (September-October 2013) in 15 districts of Bangui and during the second collection (November-December 2013) in four districts

four samples their species could not be determined but they were identified as being part of the An. gambiae sister taxa. No An. arabiensis mosquitoes were present in this collection. The 60 specimens that could not be identified with these assays were characterized using the nuclear internal transcribed spacer 2 (ITS2) based diagnostics [28]. In anophelines the length of the amplified ITS2 fragments varies according to the species and representative amplicons of three different sizes were obtained from the tested samples and sequenced. Sequence comparison by BLASTN against public databases identified the approximately 750 bp fragment as originating from An. funestus $(\mathrm{n}=44)$ and an approximately $650 \mathrm{bp}$ fragment led to the identification of An. coustani $(\mathrm{n}=2)$ mosquitoes. Fragments of 600 bp were characteristic for mosquitoes belonging to the An. gambiae sister taxa.

To determine the species of those mosquitoes that could not be identified with the ITS2-based assay $(\mathrm{n}=14)$, a region of the mitochondrial cytochrome oxidase subunit I (COI) gene was amplified by PCR and sequenced. The sequences of the amplicons were compared to the Barcode of Life database and permitted the identification of $A n$. pharoensis $(\mathrm{n}=11)$ and also confirmed the former identification of the An. coustani mosquitoes. Three samples could not be typed, probably due to poor DNA quality. COI based species identification has gained increasing importance due to the universal primers that amplify the gene in many species. The degree of variations found in the sequenced amplicons permits the distinction of many animals and has been shown to be useful for mosquito species identification [29].

Analysis of the paracentric 2La inversion performed on 183 specimen of the An. gambiae sister taxa showed that $37.7 \%$ presented the karyotype $2 \mathrm{~L}+/ 2 \mathrm{La}(\mathrm{n}=69)$, $39.3 \% 2 \mathrm{~L}+/ 2 \mathrm{~L}+(\mathrm{n}=72)$ and $21.3 \% 2 \mathrm{La} / 2 \mathrm{La}(\mathrm{n}=39)$. Three samples did not give results.

The detection of the $k d r$ insecticide resistance allele L1014F frequency ( $k d r-w$ type) in 183 mosquitoes of the An. gambiae sister taxa revealed a high prevalence of this resistance conferring variant present in the voltage-gated sodium channel encoding para gene [30]. Thus $92.3 \%$ of the An. gambiae sister taxa mosquitoes presented a homozygous resistant profile of the type RR $(n=169)$, $4.4 \%$ a heterozygous profile RS $(\mathrm{n}=8)$. Six samples did not give results. None of the tested An. gambiae sister taxa mosquitoes was found to be homozygous for the insecticide sensitive wild type $k d r$ allele L1014.

Detection of $P$. falciparum parasites in the 183 mosquitoes of the An. gambiae sister taxa by PCR [22-24] revealed 9 parasite positive mosquitoes, one was captured by PSC and 8 by HLC (infection rate $=4.91 \%$ ). In terms of indoor-captured $(\mathrm{n}=104)$ and outdoorcaptured mosquitoes $(\mathrm{n}=79)$, this rate corresponded to $5.77 \%(\mathrm{n}=6)$ and $3.79 \%(\mathrm{n}=3)($ Chi square $=0.33$, 
$p=0.56$ ) respectively (Fig. 4). All molecular attribute data for mosquitoes of the second collection (November-December 2013) is available (Additional file 5: Table S1).

\section{Discussion}

This study provides for the first time in at least 50 years a characterization of potential malaria vectors present in the CAR, and a first evaluation of their status of insecticide resistance considering the presence of the $k d r$ insecticide resistance allele L1014F. These results showed that in Bangui the most efficient malaria vectors, An. coluzzii, An. gambiae and An. funestus, are sympatric and play an important role in malaria transmission. They appear well adapted to humans and their environment, being highly anthropophilic. In addition, secondary vector species such as An. coustani were also detected and could play a significant role in transmission. Similar Anopheles diversity was also reported from Cameroon [2], Gabon [31], Chad [32] and in the Democratic Republic of Congo [33].

In this study, data about anopheline aggressiveness showed an important activity of mosquitoes of the $A n$. gambiae sister taxa and An. funestus during the early night hours (particularly after midnight), which generally corresponds to the period when people are in bed. Evaluation of the ITN coverage showed that in $201466.8 \%$ of the population regularly used bed nets during the night, however by observation during the current surveys many of these bed nets were in poor physical condition, therefore representing an inefficient barrier for blood-seeking mosquitoes.

Anopheles densities were high in certain districts and local variations in the number and species of captured anophelines by HLC were detected. Similar observations have been made in Senegal [34], Benin [35] and Cameroon [36]. Anopheles gambiae sister taxa are known to exhibit opportunistic feeding behaviour and therefore blood meal identification is important in understanding vectorial capacity of malaria vectors and transmission dynamics [37]. In this study, mosquitoes of the An. gambiae sister taxa were highly anthropophilic, even though most of the households kept cattle near their houses and no difference of anthropophilic biting rates was observed according to the district. In addition, a high level of infection rate was observed, which was greater in mosquitoes captured indoors than outdoors.

The genomic studies, done with the mosquitoes of the second collection, showed the predominance of An. gambiae $(\mathrm{n}=175)$, with very little presence of $A n$. coluzzii $(\mathrm{n}=4)$. Other studies also demonstrated the predominance of An. gambiae in this part of Central Africa. An. gambiae have a larval development that usually requires high rainfall in contrast to the An. coluzzii, generally more adapted to drier conditions with a larval development very similar to An. arabiensis [11, 38, 39].

In the two sample sets Plasmodium parasites were detected by either ELISA-CSP (in the first collection) or by PCR (in the second collection) and the differences in the infection rates displayed higher parasite prevalence in mosquitoes of the An. gambiae sister taxa in the first collection. This difference is probably not due to a sensitivity problem. Plasmodium detection by PCR, done on DNA prepared from individual mosquitoes, was shown to be more sensitive than ELISA-CSP [40] and could even have detected parasites present in a freshly taken blood meal whereas ELISA-CSP, done on dissected head-thorax fractions, detects established Plasmodium infections.

The study revealed a high prevalence of the $k d r-w$ L1014F mutated allele in mosquitoes of the An. gambiae sister taxa in Bangui, similar to the observed rates reported in other countries [30, 41-43]. Several studies have suggested that the use of agricultural pesticides favored the emergence of $k d r$ mutations and facilitated the spread of the insecticide resistance associated allele within mosquito populations [44]. Although this point was not specifically investigated, it is possible that changes in agricultural practice in certain district of Bangui have contributed to the emergence of this resistance. On the other hand, the exposure to the insecticides of ITNs may also be a factor responsible for the $k d r$ allele diffusion $[35,45]$. Additional studies would be needed to investigate the origin of $k d r$ allele diffusion and their impact on Anopheles insecticide susceptibility.

In CAR, the WHO malaria control gold standards were not met [1]. Due to political instability, the use of anti-malarial drugs and of ITNs by the population was not high and most malaria attacks were not treated. In many countries, the choice of the anti-malarial drug (artemisinin-based combinations) used for the first-line treatment and the universal deployment of ITNs were the most important factors responsible for reduction of malaria infection and malaria morbidity [46]. The current situation in Bangui brings to mind the status observed in different countries before vector control intervention $[34,47,48]$. In these countries the introduction of untreated bed nets as first vector control interventions were reported to shift the biting hours, resulting in an increase of the exophilic tendency [7, 42, 49]. However, the absence of structured vector control strategies, such as ITNs of good quality, is probably one of the origins of this high anthropophilic rate observed in Bangui. Therefore, considerable efforts will be needed to reduce the level of man-vector contact to decrease malaria transmission as it has been observed in other countries $[47,50]$. 


\section{Conclusion}

The knowledge of malaria vector biology is a prerequisite for the design and implementation of current and future vector control strategies. Control methods to be put in place have to take into account the different vector populations but also the possibility that these various mosquito species or populations could transmit different Plasmodium genotypes carrying their resistance alleles. CAR is in a difficult political situation and faces a malaria epidemiological situation that is almost catastrophic. Thus, this preliminary study raises important points for further investigations and decisions.

\section{Additional files}

Additional file 1. Predominant anopheline species captured in 15 districts of Bangui by Human Landing Catch (September-October 2013).

Additional file 2. Number of Anopheles collected by Human Landing Catch in 15 districts of Bangui (September-October 2013).

Additional file 3. Anophelines collected by Pyrethrum Spray Catch (PSC) in 15 districts of Bangui (September-October 2013). Blood-fed females were identified and blood meal origin was determined by enzyme-linked immunosorbent assay (ELISA).

Additional file 4. All Anopheles mosquitoes collected indoors and outdoors by Human Landing Catch in 15 districts of Bangui (SeptemberOctober 2013) were tested by ELISA-CSP to determine their Plasmodium infection status and to calculate their circumsporozoite rates.

Additional file 5: Table S1. Molecular attribute data for mosquitoes collected in 4 districts of Bangui (November-December 2013).

\section{Abbreviations}

CAR: Central African Republic; HLC: human landing catch; PSC: pyrethrum spray catch; CSP: circumsporozoite protein; ITN: insecticide-treated net; bp: base pairs; $\mathrm{Cl}$ : confidence interval.

\section{Authors' contributions}

MON and KV designed the study. MLS and MON performed the field work. MLS, IH and KE performed the laboratory work. KE and MON analysed the data. KE and MON drafted the manuscript with contributions from MK and KV. MON supervised the study. All the authors read and approved the final manuscript.

\section{Author details}

1 G4 Malaria Group, Institut Pasteur of Bangui, BP 923, Bangui, Central African Republic. ${ }^{2}$ G4 Malaria Group, Institut Pasteur of Madagascar, BP 1274, Ambohitrakely, 101 Antananarivo, Madagascar. ${ }^{3}$ Unit of Insect Vector Genetics and Genomics, Department of Parasites and Insect Vectors, Institut Pasteur, 28 rue du Docteur Roux, 75015 Paris, France. ${ }^{4}$ Unit of Hosts, Vectors and Pathogens (URA3012), CNRS, 28 rue du Docteur Roux, 75015 Paris, France. ${ }^{5}$ Faculté des Sciences et Techniques, Université d'Abomey Calavi, Cotonou, Benin. ${ }^{6}$ Virology Department, Institut Pasteur de Bangui, Bangui, Central African Republic. ${ }^{7}$ Institut Pasteur de la Guyane, 23 Avenue Pasteur, BP 6010, 97306 Cayenne Cedex, French-Guiana.

\section{Acknowledgements}

The authors are grateful to the data collection teams in Bangui and to the volunteer capturers for their cooperation in this study and for their compliance. They thank all the facilitators and participants for their constructive critical assistance during the validation of the project (Djibrine Djallé) and the responsible security (Patrick Sanchez). Special thanks go to all members of the G4 Group Team for their participation in field and laboratory work at different stages of the project. The authors thank Michelle M. Riehle, University of Minnesota, for critical reading of the manuscript.

\section{Competing interests}

The authors declare that they have no competing interests.

\section{Ethical approval}

Ethical approval was given by the CAR National Ethic Committee (Authorization No 0101MSANP/CNE2013). Prior to both collections, permission was sought from the village elders; village meetings were conducted to explain the purpose of the study and participation was requested. Verbal consent was obtained to collect mosquitoes from houses.

\section{Funding}

This work was supported by the Division International of Institut Pasteur International Network (DI- IPIN/RIIP-G4 Group) to MON. This work received financial support to KDV from the European Research Council, Support for frontier research, Advanced Grant \#323173 and from the French Laboratoire d'Excellence "Integrative Biology of Emerging Infectious Diseases" \#ANR-10LABX-62-IBEID Grant. The funders had no role in study design, data collection and analysis, decision to publish, or preparation of the manuscript.

Received: 22 March 2016 Accepted: 5 July 2016

Published online: 26 July 2016

\section{References}

1. World Health Organization. World malaria report 2014. Geneva: World Health Organization; 2014. p. 242.

2. Mouchet J, Gariou J. Répartition géographique et écologique des anophèles au Cameroun. Bull Soc Path Exot. 1961;54:103-18.

3. Mouchet J, Carnevale P, Coosemans MH, Julvez J, Manguin S. Biodiversité du paludisme dans le monde. Paris: Eurotext John Libbey; 2004. p. 428.

4. Rapport MSF. République centrafricaine: une crise silencieuse. [http:// www.msf.fr/actualite/publications/rapport-republique-centrafricainecrise-silencieuse] Accessed Jan 2016.

5. World Health Organization. World malaria report 2013. Geneva: World Health Organization; 2013. p. 284.

6. Greenwood BM. Control to elimination: implications for malaria research. Trends Parasitol. 2008;24:449-54.

7. Trape JF, Tall A, Diagne N, Ndiath O, Ly AB, Faye J, et al. Malaria morbidity and pyrethroid resistance after the introduction of insecticide-treated bednets and artemisinin-based combination therapies: a longitudinal study. Lancet Infect Dis. 2011;11:925-32.

8. Fontenille D, Lochouarn $\mathrm{L}$. The complexity of the malaria vectorial system in Africa. Parassitologia. 1999;41:267-71.

9. Fontenille D, Cohuet A, Awono-Ambene PH, Antonio-Nkondjio C, Wondji C, Kengne P, et al. Systematics and biology of Anopheles vectors of Plasmodium in Africa, recent data. Med Trop. 2003;63:247-53 (in French).

10. Toure YT, Petrarca V, Traore SF, Coulibaly A, Maiga HM, Sankare O, et al. The distribution and inversion polymorphism of chromosomally recognized taxa of the Anopheles gambiae complex in Mali, West Africa. Parassitologia. 1998;40:477-511.

11. Ndiath MO, Brengues C, Konate L, Sokhna C, Boudin C, Trape JF, et al. Dynamics of transmission of Plasmodium falciparum by Anopheles arabiensis and the molecular forms $\mathrm{M}$ and $\mathrm{S}$ of Anopheles gambiae in Dielmo Senegal. Malar J. 2008;7:136

12. Coluzzi M, Sabatini A, Petrarca V, Di Deco MA. Chromosomal differentiation and adaptation to human environments in the Anopheles gambiae complex. Trans R Soc Trop Med Hyg. 1979;73:483-97.

13. Ngoagouni C, Kamgang B, Manirakiza A, Nangouma A, Paupy C, Nakoune E, et al. Entomological profile of yellow fever epidemics in the Central African Republic, 2006-2010. Parasit Vectors. 2012;5:175.

14. WHO. Country profiles: Central African Republic [http://www.who.int/ countries/caf/en/] Accessed May 2016.

15. Kollias N, Gillies R, Moran M, Kochevar IE, Anderson RR. Endogenous skin fluorescence includes bands that may serve as quantitative markers of aging and photoaging. J Invest Dermatol. 1998;111:776-80. 
16. Beier JC, Perkins PV, Wirtz RA, Koros J, Diggs D, Gargan TP 2nd, et al. Bloodmeal identification by direct enzyme-linked immunosorbent assay (ELISA), tested on Anopheles (Diptera: Culicidae) in Kenya. J Med Entomol. 1988;25:9-16.

17. Burkot TR, Zavala F, Gwadz RW, Collins FH, Nussenzweig RS, Roberts DR. Identification of malaria-infected mosquitoes by a two-site enzymelinked immunosorbent assay. Am J Trop Med Hyg. 1984;33:227-31.

18. Riehle MM, Guelbeogo WM, Gneme A, Eiglmeier K, Holm I, Bischoff E, et al. A cryptic subgroup of Anopheles gambiae is highly susceptible to human malaria parasites. Science. 2011;331:596-8.

19. Santolamazza F, Mancini E, Simard F, Qi Y, Tu Z, della Torre A. Insertion polymorphisms of SINE200 retrotransposons within speciation islands of Anopheles gambiae molecular forms. Malar J. 2008;7:163.

20. Fanello C, Santolamazza F, della Torre A. Simultaneous identification of species and molecular forms of the Anopheles gambiae complex by PCRRFLP. Med Vet Entomol. 2002;16:461-4.

21. White BJ, Santolamazza F, Kamau L, Pombi M, Grushko O, Mouline K, et al. Molecular karyotyping of the $2 \mathrm{La}$ inversion in Anopheles gambiae. Am J Trop Med Hyg. 2007;76:334-9.

22. Fornadel CM, Norris LC, Franco V, Norris DE. Unexpected anthropophily in the potential secondary malaria vectors Anopheles coustani s.l. and Anopheles squamosus in Macha, Zambia. Vector Borne Zoonotic Dis. 2011;11:1173-9.

23. Hasan AU, Suguri S, Sattabongkot J, Fujimoto C, Amakawa M, Harada M, et al. Implementation of a novel PCR based method for detecting malaria parasites from naturally infected mosquitoes in Papua New Guinea. Malar J. 2009;8:182.

24. Coulibaly B, Kone R, Barry MS, Emerson B, Coulibaly MB, Niare O, et al. Malaria vector populations across ecological zones in Guinea Conakry and Mali, West Africa. Malar J. 2016;15:191.

25. Beebe NW, Saul A. Discrimination of all members of the Anopheles punctulatus complex by polymerase chain reaction-restriction fragment length polymorphism analysis. Am J Trop Med Hyg. 1995;53:478-81.

26. Kirsten M, Inger L, Hedvig P, Artur S, Mats W (Eds.): Malaria research and reference reagent resource center (MR4). Methods in malaria research, 5th edn. 2008.

27. Ratnasingham S, Hebert PD. The barcode of life data system. Mol Ecol Notes. 2007;7:355-364. (http://www.barcodinglife.org). Accessed Oct 2015.

28. Koekemoer LL, Kamau L, Hunt RH, Coetzee M. A cocktail polymerase chain reaction assay to identify members of the Anopheles funestus (Diptera: Culicidae) group. Am J Trop Med Hyg. 2002;66:804-11.

29. Chan A, Chiang LP, Hapuarachchi HC, Tan CH, Pang SC, Lee R, et al. DNA barcoding: complementing morphological identification of mosquito species in Singapore. Parasit Vectors. 2014;7:569.

30. Santolamazza F, Calzetta M, Etang J, Barrese E, Dia I, Caccone A, et al. Distribution of knock-down resistance mutations in Anopheles gambiae molecular forms in west and west-central Africa. Malar J. 2008;7:74.

31. Mourou JR, Coffinet T, Jarjaval F, Pradines B, Amalvict R, Rogier C, et al. Malaria transmission and insecticide resistance of Anopheles gambiae in Libreville and Port-Gentil, Gabon. Malar J. 2010;9:321.

32. Kerah-Hinzoumbe C, Peka M, Antonio-Nkondjio C, Donan-Gouni I, Awono-Ambene P, Same-Ekobo A, et al. Malaria vectors and transmission dynamics in Goulmoun, a rural city in south-western Chad. BMC Infect Dis. 2009;9:71.

33. Trape JF. Malaria and urbanization in central Africa: the example of Brazzaville. Part IV. Parasitological and serological surveys in urban and surrounding rural areas. Trans R Soc Trop Med Hyg. 1987;81(Suppl 2):26-33.

34. Lemasson JJ, Fontenille D, Lochouarn L, Dia I, Simard F, Ba K, et al. Comparison of behavior and vector efficiency of Anopheles gambiae and An. arabiensis (Diptera:Culicidae) in Barkedji, a Sahelian area of Senegal. J Med Entomol. 1997;34:396-403.

35. Corbel V, Akogbeto M, Damien GB, Djenontin A, Chandre F, Rogier C, et al. Combination of malaria vector control interventions in pyrethroid resistance area in Benin: a cluster randomised controlled trial. Lancet Infect Dis. 2012;12:617-26.
36. Antonio-Nkondjio C, Defo-Talom B, Tagne-Fotso R, Tene-Fossog B, Ndo C, Lehman LG, et al. High mosquito burden and malaria transmission in a district of the city of Douala, Cameroon. BMC Infect Dis. 2012;12:275.

37. Bryan JH, Petrarca V, Di Deco MA, Coluzzi M. Adult behaviour of members of the Anopheles gambiae complex in the Gambia with special reference to An. melas and its chromosomal variants. Parassitologia. 1987:29:221-49.

38. Wondji C, Simard F, Fontenille D. Evidence for genetic differentiation between the molecular forms $\mathrm{M}$ and $\mathrm{S}$ within the forest chromosomal form of Anopheles gambiae in an area of sympatry. Insect Mol Biol. 2002;11:11-9.

39. Dabire KR, Sawadodgo S, Diabate A, Toe KH, Kengne P, Ouari A, et al. Assortative mating in mixed swarms of the mosquito Anopheles gambiae s.s. $\mathrm{M}$ and $\mathrm{S}$ molecular forms, in Burkina Faso, West Africa. Med Vet Entomol. 2013;27:298-312.

40. Bassene $H$, Kengne P, Ndiath MO, Sokhna C, Dupressoir T, Fontenille D, et al. Comparison of PCR, ELISA-CSP and direct microscopic observation methods for the detection of Plasmodium falciparum sporozoites in Anopheles gambiae M in Senegal. Bull Soc Pathol Exot. 2009;102:233-7 (in French).

41. Ranson H, N'Guessan R, Lines J, Moiroux N, Nkuni Z, Corbel V. Pyrethroid resistance in African anopheline mosquitoes: what are the implications for malaria control? Trends Parasitol. 2011;27:91-8.

42. Ndiath MO, Mazenot C, Sokhna C, Trape JF. How the malaria vector Anopheles gambiae adapts to the use of insecticide-treated nets by African populations. PLoS One. 2014;9:e97700.

43. Ndiath MO, Cailleau A, Orlandi-Pradines E, Bessell P, Pages F, Trape JF, et al. Emerging knock-down resistance in Anopheles arabiensis populations of Dakar, Senegal: first evidence of a high prevalence of kdr-e mutation in West African urban area. Malar J. 2015;14:364.

44. Diabate A, Baldet T, Chandre F, Akoobeto M, Guiguemde TR, Darriet F, et al. The role of agricultural use of insecticides in resistance to pyrethroids in Anopheles gambiae s.I. in Burkina Faso. Am J Trop Med Hyg. 2002;67:617-22.

45. Curtis CF, Jana-Kara B, Maxwell CA. Insecticide treated nets: impact on vector populations and relevance of initial intensity of transmission and pyrethroid resistance. J Vector Borne Dis. 2003;40:1-8.

46. Roberts L, Enserink M. Malaria. Did they really say... eradication? Science. 2007;318:1544-5.

47. Trape JF, Tall A, Sokhna C, Ly AB, Diagne N, Ndiath O, et al. The rise and fall of malaria in a West African rural community, Dielmo, Senegal, from 1990 to 2012: a 22 year longitudinal study. Lancet Infect Dis. 2014;14:476-88.

48. Fontenille D, Lochouarn L, Diagne N, Sokhna C, Lemasson JJ, Diatta M, et al. High annual and seasonal variations in malaria transmission by anophelines and vector species composition in Dielmo, a holoendemic area in Senegal. Am J Trop Med Hyg. 1997;56:247-53.

49. Gatton ML, Chitnis N, Churcher T, Donnelly MJ, Ghani AC, Godfray HC, et al. The importance of mosquito behavioural adaptations to malaria control in Africa. Evolution. 2013;67:1218-30.

50. Ceesay SJ, Casals-Pascual C, Erskine J, Anya SE, Duah NO, Fulford AJ, et al. Changes in malaria indices between 1999 and 2007 in The Gambia: a retrospective analysis. Lancet. 2008;372:1545-54

\section{Submit your next manuscript to BioMed Central and we will help you at every step:}

- We accept pre-submission inquiries

- Our selector tool helps you to find the most relevant journal

- We provide round the clock customer support

- Convenient online submission

- Thorough peer review

- Inclusion in PubMed and all major indexing services

- Maximum visibility for your research

Submit your manuscript at www.biomedcentral.com/submit 